\title{
Dokuzuncu Sınıf Öğrencilerinin Rutin Olmayan Problem Çözme Becerileri: Deneysel Bir Çalışma*
}

\author{
Non-Routine Problem Solving Skills of Ninth Grade \\ Students: An Experimental Study*
}

\author{
Serkan GÜRSAN ${ }^{\mathrm{a}}$, Yeliz YAZGAN ${ }^{\mathrm{b}}$
}

Öz

Bu çalışmada, deneysel bir rutin olmayan problem çözme eğitiminin dokuzuncu sınıf öğrencilerinin strateji kullanımı ve bu tür problemleri çözmedeki başarılarına etkisi incelenmiştir. Araştırmada tek grup ön test - son test deneysel desen kullanılmıştır. Ön ve son test sekiz açık uçlu rutin olmayan problemden oluşmuştur. Ögrrenciler 12 ders saati süren eğitim sırasında 60 rutin olmayan problem çözmüşlerdir. Çalışmada tahmin ve kontrol, sistematik liste yapma, geriye doğru çalışma, bağıntı bulma, problemi basitleștirme, muhakeme etme, denklem kurma ve sekil cizme stratejilerinin kullanımını gerektiren sorular kullanılmıștır. Verilerin analizinde betimsel istatistikler, normallik testleri ve ilişkili örneklemler için t-testi kullanılmıştır. Bulgular iki önemli noktaya işaret etmektedir: i) Dokuzuncu sınıf öğrencileri herhangi bir müdahale olmaksızın rutin olmayan problem çözmede oldukça başarılıdırlar, ii) verilen eğitim öğrencilerin bu konudaki başarılarını artıırmıştır.

Anahtar Kelimeler: Dokuzuncu Sınıf Öğrencileri, Problem Çözme, Rutin Olmayan Problem, Problem Çözme Stratejileri

\begin{abstract}
In this study, the effect of an experimental intervention about non-routine problem solving on ninth grade students' strategy use and success in solving these kinds of problems were examined. One group pretestposttest experimental design was used in the study. Pretest and posttest consisted of eight open-ended non-routine problems. Students solved 60 non-routine problems during the intervention that lasted 12 class periods. Problems requiring to use of quess and check, make a systematic list, work backward, look for a pattern, simplify the problem, logical reasoning, write an equation, and make a drawing strategies were used in the study. For the analysis of data, descriptive statistics, normality tests, and paired sample t-test were used. Findings highlight two important points: i) Ninth graders were quite successful in solving non-routine problems without any intervention, ii) given intervention increased students' success in this respect.
\end{abstract}

Keywords: Ninth Grade Students, Problem Solving, Non-Routine Problem, Problem Solving Strategies

\section{Makale Hakkında}

Tür: Araștırma

Geliş Tarihi: 20 Ekim 2019 Kabul Tarihi: 7 Mayıs 2020 Yayın Tarihi: 4 Temmuz 2020 DOI:

Sorumlu Yazar Yeliz YAZGAN Bursa Uludağ Üniversitesi Bursa/Türkiye. E-posta: yazgany@uludag.edu.tr

\section{About the Article}

Type: Research Received: 20 October 2020 Accepted: 7 May 2020 Published: 4 July 2020 DOI:

Corresponding Author Yeliz YAZGAN

Bursa Uludag University Bursa/Turkey.

E-mail: yazgany@uludag.edu.tr

\section{Önerilen APA Atıf Biçimi / Suggested APA Citation}

Gürsan, S., \& Yazgan, Y. (2020). Dokuzuncu sınıf öğrencilerinin rutin olmayan problem çözme becerileri: Deneysel bir çalışma. Academy Journal of Educational Sciences, 4(1), 23-29. http://dx.doi.org/10.31805/acjes.632560 


\section{Giriş}

Eğitim ve öğretim sürecinde nitelikli bir sonucun gerçekleşebilmesi için bireylerin bilgiyi edinme, kullanma ve geliştirmeleri önem taşımaktadır. Bu süreçte problem çözmenin önemi yadsınamaz. Sadece matematikte değil günlük yaşantımızda da sık sık karşılaștığımız problem, "yașayan bir canlının bir hedefinin olduğu ancak hedefine nasıl ulaşacağını bilmediği zaman ortaya çıkar" (Novick ve Bassok, 2005, s. 321). Problem çözme ise "net olarak tasarlanan fakat hemen ulașılamayan bir hedefe varmak için kontrollü etkinliklerle araştırma yapma" sürecidir (Altun, 2016, s.87). Problem çözme becerisi, insan hayatının en önemli bileşenlerinden biridir. Bu yüzden matematik programları (örn. Milli Eğitim Bakanlığı, 2018), uluslararası düzeyde yapılan PISA gibi sınavlarla bağlantılı dokümanlar (örn. Organisation for Economic Co-operation and Development [OECD], 2014), yine uluslararası düzeyde değerlendirme standartları (örn. National Council of Teachers of Mathematics [NCTM], 2000) bu becerinin öğrencilere kazandırılması gerektiğini ifade eder.

Matematik eğitimi literatüründe problem türleriyle ilgili en sık karşılaşılan sınıflandırma, bu çalışma kapsamında da yer verilen rutin ve rutin olmayan problem ayrımıdır. Rutin problemler, çoğunlukla dört işlem kullanma becerisine dayalı, akıl yürütme ya da muhakeme etme süreci gerektirmeyen, çözüm için gerekli kural ve algoritmaların önceden bilindiği türden problemlerdir (Polya, 1957). Ders kitaplarındaki problemlerin büyük bir çoğunluğu rutin problemdir. "12 ve 8 sayılarına bölündüğünde 7 kalanını veren en küçük sayı nedir?" problemi buna bir örnek olarak verilebilir. Rutin olmayan problemler ise, işlem becerisinin ötesinde daha üst düzeyde düşünme becerisi gerektiren, tahmin edilebilir veya daha önceden kullanılmış bir çözüm yöntemi kullanılarak çözülemeyen problemlerdir (Woodward vd., 2012). Örneğin "Meyve satan bir çocuğun elinde 2, 3 ve 7 kilogramlık kütlelerden birer tane ve bir de terazi var. Sadece bunları kullanarak 1 kilogramdan 9 kilograma kadar olan tüm kütleleri tartabilir mi?" problemi bu türden bir problemdir.

Krulik ve Rudnick (1993) iyi bir problemin özelliklerini şöyle sıralamaktadır: i) Öğrenci için ilginç ve meydan okuyucu olmalı, ii) eleştirel analiz ve gözlem becerilerini gerektirmeli, iii) tartışma ve etkileşim için bir fırsat sağlamalı, iv) çözümü matematiksel bir kavramın kavrayışını veya matematiksel bir becerinin uygulamasını içermeli, v) matematiksel bir ilke ve/ veya genellemeye yönlendirmeli ve vi) farklı çözüm yolları ve cevaplara elverişli olmalıdır. Rutin olmayan problemler bu özelliklerin hepsini veya birçoğunu taşır. Bundan dolayı, ileri gelen matematik eğitimcileri, öğrencilerin muhakeme ve problem çözme becerilerini geliştirmek için öğretim ortamlarında, ders kitaplarında, programlarda rutin olmayan problemlere yer verilmesi gerektiğini savunmaktadır (örn. London, 2007; Polya, 1957; Sriraman, 2004).

Genel anlamda problem çözme stratejileri, birey tarafından geliştirilen ve etkinleştirildiklerinde bir grup ilişkili ödevle ilgili bilişsel etkinliği etkileyen zihinsel süreçlerdir (Lawson, 1990). Rutin olmayan problem çözme stratejileri ise, bir çözüme giden yolları belirtmek amacıyla, rutin olmayan problemlerin yönlerini keşfetmek, analiz etmek ve derinlemesine incelemek için kullanılan prosedürler olarak tanımlanabilir (Nancarrow, 2004). Bu stratejiler, rutin olmayan problemleri çözerken öğrenciler tarafından deneyimlenen matematiksel süreçte çok etkin bir rol oynarlar. Rutin olmayan problem çözme stratejileri çözümü garantilemez, ne yapılması gerektiği ile ilgili katı olmayan önerilerdir. Bu stratejiler sadece özel bir konu alanındaki belli türde sorulara uygulanmazlar. Aksine, rutin olmayan problem çözme stratejileri farklı tür soru ve konu alanları boyunca uygulanabilirler (Tiong, Hedberg ve Lioe, 2005). Belli başlı rutin olmayan problem çözme stratejileri şöyle sıralanabilir: Canlandırma, bağıntı bulma, sistematik liste yapma, geriye doğru çalışma, şekil veya diyagram çizme, denklem veya eşitsizlik kurma, problemi basitleştirme, tablo yapma, eleme, muhakeme etme, matris mantığı ve tahmin (Fang, Ho, Lioe, Wong ve Tiong, 2009; Herr ve Johnson, 2002; Leng, 2008; Posamentier ve Krulik, 2008).

Rutin olmayan problem çözme ile ilgili literatürde yapılmış birçok araştırma vardır ve bu araştırmaların kapsamları şu şekilde özetlenebilir: Herhangi bir eğitim verilmeksizin öğrencilerin mevcut rutin olmayan problem çözme becerilerini inceleyen çalışmalar (örn. Mabilangan, Limjap ve Belecina, 2012), rutin olmayan problem çözme ile ilgili verilen eğitimin etkilerini inceleyen çalışmalar (örn. Lee, Yeo ve Hong, 2014), yüksek veya düşük başarılı öğrencilerin rutin olmayan problem çözerken gösterdikleri davranışlarla ilgili çalışmalar (örn. Budak, 2012), rutin olmayan problem çözmede cinsiyetle ilgili farklılıkları inceleyen çalışmalar (örn. Abedalaziz, 2011) ve rutin olmayan problemlerin ve onların çözümünde kullanılan stratejilerin matematik ders kitapları ve ders programındaki yerini inceleyen çalışmalar (örn. Marchis, 2012). Farklı sınıf düzeylerinden yapılan bu çalışmaların sonuçlarına göre, öğrenciler rutin olmayan problemleri karmaşık ve zor bulmaktadır (Elia, Van den Heuvel-Panhuizen ve Kolovou, 2009). Ancak rutin olmayan problemleri içeren eğitimler öğrencilerin (özellikle düşük başarılı olanların) bu konuyla ilgili başarısını ve güven düzeyini arttırmaktadır (Ishida, 2002). Bunun yanı sıra, yüksek başarılı öğrencilerin rutin olmayan problemleri çözmede daha kararlı oldukları ve denedikleri yöntem işe yaramazsa alternatif yollar arayabildikleri gözlenmiştir (Budak, 2012). Yine rutin olmayan problemleri çözme açısından kız ve erkekler arasında anlamlı bir fark olmadığı, ders kitaplarındaki problemlerin sadece çok küçük bir yüzdesinin rutin olmayan olduğu da dikkati çeken diğer bulgulardır (Abedalaziz, 2011; Kolovou, Van den Heuvel-Panhuizen ve Bakker 2009; Marchis, 2012 ).

\section{ilgili Araştırmalar}

Daha önce de belirtildiği gibi, rutin olmayan problem çözme literatürü oldukça kapsamlıdır. Bu yüzden bu bölümde doğrudan rutin olmayan problemleri içeren ve lise düzeyinde yapılmış beş farklı çalışma ilgilerinden dolayı biraz daha ayrıntılı açıklanacaktır.

Amacı 16 yaş grubundaki yüksek başarılı öğrencilerin problem çözme yeteneklerini ve tutumlarını belirlemek olan ve Salleh ve Zakaria (2009) tarafından yapılan çalışmada, toplam 107 öğrenciye tutum ölçeği ve rutin olmayan problem çözme testi uygulanmıştır. Sonuçlar, öğrencilerin bu tür problemleri çözme becerilerinin iyi olduğunu ve problem çözmeye karşı olumlu tutum sergilediklerini göstermiştir. Ayrıca, problemi anlama, çözüm için strateji planlama, stratejiyi uygulama, doğru cevabı yazma ve problem çözmeye karşı tutum açısından kız ve erkek öğrenciler arasında anlamlı bir fark olmadığı ortaya çıkmıştır. 
Mabilangan ve diğerleri (2011) tarafından yapılan çalışmanın amacı, 5 üstün yetenekli lise öğrencisinin rutin olmayan problemleri nasıl çözdüklerini incelemektir. Öğrencilerin çözümleri, her öğrencinin en az dört farklı strateji kullandığını göstermiştir. Öğrenciler, 12 rutin olmayan problemi çözerken sekiz olası stratejiden yedisini kullanmışlardır. En fazla kullanılan strateji şekil çizme stratejisidir. Tablo yapma, sistematik liste yapma ve problemi basitleştirme diğer ön plana çıkan stratejilerdendir. Ayrıca, çalışmadaki soruları çözmedeki bașarılarına göre, üç öğrenci yetenekli, bir öğrenci geçiș döneminde (yani orta düzeyde), bir öğrenci ise acemi olarak sınıflandırılmıştır.

Bu alandaki araştırmalardan bir diğeri ise Yazgan (2013) tarafından yapılmıştır. Bu çalışmada, liselerde rutin olmayan matematik problemi çözme ve bu becerinin üniversite giriş sınavlarındaki başarıya olan katkısı incelenmiştir. Öğrencilerin rutin olmayan problem çözme yeteneklerini ölçmek için dokuz rutin olmayan problemden oluşan bir test 144 lise son sınıf öğrencisine uygulanmıştır. Bunun yanı sıra, öğrencilerin üniversiteye giriş puanları daha sonra okullarından alınmıştır. Öğrencilerin rutin olmayan problemlere verdikleri cevapların analizi, lise öğrencilerinin rutin olmayan problemleri başarıyla çözebildiklerini ve farklı stratejiler kullanabildiklerini göstermiştir. Daha da önemlisi, problem çözme testi ve üniversiteye giriş puanları kullanılarak yapılan korelasyon analizi, lise öğrencilerinin üniversite giriş sınavındaki başarıları ve rutin olmayan problem çözme yetenekleri arasında önemli bir bağın olduğunu göstermiştir

Hem deneysel eğitimin verildiği hem de dokuzuncu sınıf düzeyinde ilgili bir çalışma, Kavgacı (2016) tarafından gerçekleştirilmiştir. Bu çalışmada, rutin ve rutin olmayan matematik problemi çözme öğretiminin araştırmaya katılan dokuzuncu sınıf öğrencilerinin yaratıcılıklarının gelişimine etkisi araştırımıştır. Ayrıca, dokuzuncu sınıf öğrencilerinin rutin ve rutin olmayan problemleri çözme öğretimini almalarının bu problemleri çözmedeki becerilerine katkısı da araştırılmıştır. Çalışmanın sonucunda, verilen öğretimin araştırmaya katılan dokuzuncu sınıf öğrencilerinin rutin ve rutin olmayan problem çözme başarılarını, özel ve şekilsel yaratıcılık düzeylerini olumlu yönde etkilediği anlaşılmıştır.

Sahillioğulları (2019) tarafından yapılan bir diğer çalışmada, dokuzuncu sınıf öğrencilerinin öğrenme stilleri ile rutin olmayan problem çözme başarıları arasındaki ilişki incelenmiştir. Bunun yanı sıra öğrencilerin rutin olmayan problem hakkındaki düşünceleri de araştırılmıştır. Bu bağlamda, Kolb Öğrenme Stili Envanteri ve rutin olmayan problemler içeren Matematik Problem Çözme Testi toplam 563 öğrenciye uygulanmıştır. Ayrıca 20 öğrenci ile de rutin olmayan problemler ile ilgili görüşmeler yapılmıştır. Çalışmanın sonunda, öğrencilerin öğrenme stilleri ile rutin olmayan problem çözme başarıları arasında düşük düzeyde anlamlı bir ilişkinin olduğu anlaşılmıştır. Öğrencilerin rutin olmayan matematik problemleri hakkındaki olumlu görüşleri de rapor edilmiştir.

Lise düzeyindeki bu beş çalışmanın sonuçlarına göre, lise öğrencileri herhangi bir eğitim almasalar bile rağmen rutin olmayan problemleri çözebilmekte ve bunu yaparken farklı stratejilere başvurabilmektedirler. Ayrıca rutin olmayan problemlere genellikle olumlu bakmaktadırlar. Yine bu çalışmaların bulgularına göre, rutin olmayan problem çözme başarısı, cinsiyet ve öğrenme stilleri açısından farklılık göstermemektedir. Rutin problemlerle birlikte verilse de, rutin olmayan problemleri içeren eğitimin öğrencilerin başarılarını arttırdığı gözlenmiştir. Son olarak, bulgular rutin olmayan problem çözmenin ileri düşünce becerilerini gerektirdiğine ve bu tür soruları çözebilen öğrencilerin kritik ve yaratıcı düşünme becerilerini dil ve fen gibi sahalarda da kullanabildiklerine işaret etmektedir. Bu çalışmanın diğerlerinden en önemli farklıı̆ı̆, sadece rutin olmayan problem çözme ile ilgili deneysel bir eğitim içermesi ve bu eğitimin etkilerini hem genel olarak hem de strateji bazında incelemesidir.

Her ne kadar lise düzeyinde yapılmasa da, liseye yakın başka sınıf düzeylerinde yapılmış ilgili çalışmalar da vardır. Örneğin, Altun ve Arslan (2006) tarafından yapılan çalışmada, yedinci ve sekizinci sınıf öğrencilerine rutin olmayan matematiksel problemlerin çözümlerini öğretmek için planlanan deneysel bir çalışmanın sonuçları rapor edilmiştir. Problemi basitleştirme, tahmin ve kontrol, bağıntı bulma, şekil çizme, sistematik liste yapma ve geriye doğru çalışma stratejilerini içeren çalışmanın sonucunda bu stratejileri öğretme amacı ile hazırlanan ortamın bazı stratejilerin öğretiminde etkin olduğu bazılarında ise olmadığı görülmüştür. Yine bir başka çalışma Yılmaz (2019) tarafından sınıf öğretmeni adaylarıyla gerçekleştirilmiştir. Katıımcılar öncelikle Matematik Öğretimi dersi kapsamında çeşitli rutin olmayan problemler çözmüş ve değerlendirmişlerdir. Beş haftalık bu süreç sonunda öğretmen adaylarına rutin olmayan bir problem verilip, problemi bireysel şekilde çözmeleri istemiştir. Sonrasında çözüm süreçleri betimsel olarak analiz edilmiştir. Sonuç olarak öğretmen adaylarının sistematik liste yapma, tahmin-kontrol, muhakeme etme gibi stratejileri belirleyip uyguladıkları, bazılarının ise belirttiklerinden farklı bir strateji uyguladıkları belirlenmiştir.

\section{Araştırmanın Önemi, Amacı ve Problemleri}

Rutin olmayan problemlerin öneminin apaçık belli olmasına ve bu konuyla ilgili yoğun bir literatür olmasına rağmen, ortaöğretimdeki öğrencilerin kullandıkları rutin olmayan problem çözme stratejileriyle ilgili çalışma sayısı oldukça azdır. Hâlbuki lise öğrencilerinin problem çözme stratejileri ile ilgili dağarcıkları önemli derecede artabilir, çünkü bu öğrenciler daha karmaşık metotları kullanmada yeteneklidirler ve kendi bilgileri üzerinde düşünme becerileri de gelişmiştir. Bu nedenle onlar karşılaşacakları yeni meydan okumalarla başa çıkmak için kullanabilecekleri stratejilerle liseden ayrılmalıdırlar (NCTM, 2000). Tüm bu sebeplerden ötürü bu çalışmada rutin olmayan problem çözme eğitiminin öğrencilerin problem çözme stratejilerini kullanımlarına ve genel anlamda rutin olmayan problem çözme başarılarına etkisini incelemek amaçlanmaktadır. Bu bağlamda iki araştırma problemi belirlenmiştir:

- Rutin olmayan problem çözme eğitiminin dokuzuncu sınıf öğrencilerinin kullandıkları problem çözme stratejilerine etkisi nedir?

- Rutin olmayan problem çözme eğitiminin dokuzuncu sınıf öğrencilerinin bu tür problemleri çözmedeki başarılarına etkisi nedir?

\section{Yöntem}

\section{Araştırmanın Modeli}

Daha önce de belirtildiği üzere, bu çalışmada rutin olmayan problem çözme ile ilgili verilen bir eğitimin öğrencilerin hem strateji kullanımları hem de rutin problem çözmedeki genel 
başarıları üzerindeki etkisini incelemek amaçlanmıştır. Bu nedenle bu araștırmada tek grup ön test-son test deneysel desen kullanılmıştır. Bu desende deneysel işlemin etkisi, tek bir grup üzerinde yapılan çalışmayla ve uygulama öncesinde ön-test, sonrasında son-test kullanılmasıyla test edilir (Büyüköztürk, Kılıç-Çakmak, Akgün, Karadeniz ve Demirel, 2010).

\section{Çalışma Grubu}

Bursa il sınırlarında bulunan ortaöğretim kurumlarına devam eden dokuzuncu sınıf öğrencileri çalışmanın evrenini oluşturmaktadır. Çalışmanın örneklemi iše, Bursa ilinin merkez ilçelerinden birindeki Anadolu Lisesi seviyesinde bir lisenin fen bilimleri programında okuyan 17 dokuzuncu sınıf öğrencisinden oluşmaktadır. Birinci araştırmacı aynı zamanda matematik öğretmenleri olduğundan dolayı bu öğrencilerle çalışılmıştır. Yani örneklem seçiminde kolay ulaşılabilirlik etkili olmuştur. Bundan dolayı çalışmada seçkisiz olmayan örnekleme yöntemlerinden uygun örnekleme yöntemi kullanılmıștır (Büyüköztürk vd., 2010). Ayrıca çalıșmaya katılan öğrenciler, ÖSYM'nin yaptığı bir giriş sınavında belirli bir başarı seviyesinin üstünde olduklarından, yüksek başarılı öğrenciler olarak sınıflandırılabilirler.

\section{Veri Toplama Araçları}

Çalışmada kullanılan ön ve son test, tahmin ve kontrol, sistematik liste yapma, geriye doğru çalışma, bağıntı bulma, problemi basitleștirme, muhakeme etme, denklem kurma ve şekil çizme stratejilerinin her birine yönelik birer, toplamda sekiz rutin olmayan problemden oluşmaktadır. Farklı olmalarına rağmen, ön ve son testteki aynı numaralı soruların aynı stratejiye yönelik ve yapısal olarak paralel yapısal olmalarına dikkat edilmiştir. Örneğin, ön ve son testteki 5 numaralı sorular sırasıyla "77, 49, 36, 18, ... dizisinin son terimini bulunuz (Nasıl bulduğunuzu açıklayınız)." ve "1, 2, 4, 7, 13, 24, 44, ... dizisinin son terimini bulunuz (Nasıl bulduğunuzu açıklayınız)." şeklindedir ve ikisi de bağıntı bulma stratejisinin kullanımını hedef almaktadır.

Ön ve son testte kullanılan sorular, Yazgan ve diğerleri (2013) tarafından gerçekleştirilen bir projede kullanılmış sorulardır. Proje kapsamında 450 öğrenci ile yapılan pilot çalışmadan elde edilen veriler önce projede görev alan iki doktor öğretim üyesi tarafından ayrı ayrı (Verilerin Analizi kısmında anlatıldığı şekilde) puanlanmıştır. Bu puanlamalar kullanılarak elde edilen bulunan Kappa katsayısı 858 olarak bulunmuştur. Anlatımla ilgili gerekli düzeltmeler yapıldıktan sonra toplamda 1019 lise öğrencisine projenin esas uygulaması yapılmıştır. Esas uygulama sonucunda ön ve son testin Cronbach Alfa katsayıları sırasıyla .708 ve 694 olarak hesaplanmıştır. Sorular proje yürütücüsünün izniyle bu çalışmada da kullanılmıştır. Ayrıca geçerlik güvenirlik çalışmaları oldukça kalabalık bir öğrenci grubuyla yapıldığı ve elde edilen güvenirlik katsayıları oldukça tatmin edici olduğu için bu çalışmada tekrar geçerlik güvenirlik çalışmasına intiyaç duyulmamıştır.

\section{Deneysel isslem}

Ön testin uygulanmasından sonra, öğrencilere toplamda 12 ders saati süren rutin olmayan problem çözme eğitimi verilmiştir. Öğrencilerin okuldaki etüt saatlerinde gerçekleştirilen bu eğitimde, bir önceki bölümde bahsedilen sekiz strateji esas alınmıştır. Illk dokuz derste sadece birer stratejiye oda- klanılmış, daha sonraki üç ders boyunca stratejilerin karma bir uygulaması yapılmıştır. Öğrencilerin soruyu anlayıp uygun stratejiyi kendisinin seçerek çözmesi beklenmiştir. Sorular, boş A4 kâğıtlarına her kâğıtta bir soru olmak üzere derslerden önce hazırlanmış ve ders başlamadan öğrencilere dağıtılmıştır. Daha sonra değerlendirilmek için kâğıtlar her dersin sonunda toplanıp tarih atılarak arşivlenmiștir. Eğitim sırasında toplam 60 rutin olmayan problem çözen öğrenciler, iki veya üç kişilik sabit olmayan gruplar halinde çalışmışlardır. Sabit olmayan gruplarla çalıșılmasının nedeni şöyle açıklanabilir: Eğer öğrenciler hep aynı grupla çalışırlarsa, grup içindeki rollerini değiştirmek istemeyebilirler. Bu nedenle gruptaki herkesin birbiriyle ilgili sabit beklenti ve fikirleri oluşabilir. Örneğin bir gruptaki bir öğrenci problem çözümünde sürekli etkin bir rol üstelenirse, grubun diğer üyeleri ona güvenerek daha sonra pasif kalabilir. Ama gruplar değiştirilirse öğrenciler yeni roller oluşturma ve kişileraraSı becerilerini geliştirme fırsatına sahip olurlar (Hawkins, Truscott ve Abebe, 2019).

\section{Verilerin Analizi}

Ön ve son test değerlendirilirken, önce her soru bazında öğrenci çözümleri genel olarak incelenmiș ve bir puanlama anahtarı oluşturulmuştur (EK 1). Bu puanlama anahtarında doğru cevaplanan sorulara 2 puan, doğru yöntem kullanıldığı halde sonuca ulaşılamayan sorulara 1 puan, boș bırakılmış ya da yanlış yapılmış sorulara ise o puan verilmiştir. Yani öğrencilerin ön ve son-testten elde edebilecekleri en yüksek puan 16 'dır.

Strateji bazında başarı değerlendirilirken, her bir soru bir strateji ile bağlantıı düşünülmüș, tüm öğrencilerin o stratejiden aldıkları puanların toplamı hesaplanmıştır. Daha sonra bu toplam puanın, o stratejiden elde edilebilecek maksimum toplam puanın yüzde kaçı olduğu hesaplanmıştır. Bahsedilen maksimum toplam puan hesaplanırken öğrenci sayısı (17) ile bir stratejiden bir öğrencinin alabileceği maksimum puan (2) çarpılmıştır. Böylece, deney öncesi ve sonrasında strateji bazındaki başarı yüzdeleri hesaplanmıştır.

Genel toplam puanlar kullanılarak, öncelikle ön ve son-testle ilgili aritmetik ortalama ve standart sapmalar hesaplanmıştır. Daha sonra, ön ve son test sonuçları normallik testine tabi tutulmuş, ön ve son-test ortalamalarını karşılaştırmak amacıyla ilișkili örneklemler için $t$-testi kullanılmıștır.

\section{Araştırma Etiği}

Bu araştırmanın planlanma, uygulama ve raporlama süreçlerinin tamamında "Yükseköğretim Kurumları Bilimsel Araştırma ve Yayın Etiği Yönergesi" kapsamında uyulması belirtilen tüm kurallara uyulmuştur. Yönergenin ikinci bölümü olan "Bilimsel Araştırma ve Yayın Etiğine Aykırı Eylemler" başlığı altında belirtilen eylemlerden hiçbiri gerçekleştirilmemiştir.

\section{Bulgular}

Daha önceki paragrafta da belirtildiği üzere, parametrik veya parametrik olmayan testlerden hangilerinin kullanılacağına karar vermek için uygulanan normallik testi sonuçları Tablo 1'de sunulmaktadır.

Tablo 1'de sunulan Shapiro-Wilk testi sonuçları, ön ve sontest sonuçlarının normal dağıldığını göstermektedir. 
Tablo 1. Öğrencilerin ön test ve son test sonuçlarının normallik testi sonuçları

\begin{tabular}{lrrr}
\hline & \multicolumn{3}{c}{ Shapiro-Wilk } \\
\hline & İstatistik & sd & $p$ \\
\hline Ön test & .950 & 17 & .457 \\
\hline Son test & .944 & 17 & .368 \\
\hline
\end{tabular}

Birinci Probleme ilişkin Bulgular

Deney grubundaki öğrencilerin ön testte sergiledikleri strateji bazındaki başarı yüzdeleri Tablo z'de görülmektedir.

Tablo 2. Deney grubundaki öğrencilerin ön testteki strateji kullanımları ile ilgili başarı yüzdeleri

\begin{tabular}{lrrr}
\hline & \multicolumn{3}{c}{ Ön test } \\
\cline { 2 - 4 } Stratejiler & $\begin{array}{r}\text { Elde edilen } \\
\text { puan }\end{array}$ & $\begin{array}{r}\text { Maksimum } \\
\text { puan }\end{array}$ & $\begin{array}{r}\text { Bašarı } \\
\text { yüzdesi (\%) }\end{array}$ \\
\hline Sistematik liste yapma & 10 & 34 & 29 \\
\hline Tahmin ve kontrol & 34 & 34 & 100 \\
\hline Şekil çizme & 26 & 34 & 77 \\
\hline Denklem kurma & 24 & 34 & 70 \\
\hline Bağıntı bulma & 18 & 34 & 53 \\
\hline Geriye doğru çalışma & 3 & 34 & 9 \\
\hline Muhakeme etme & 28 & 34 & 82 \\
\hline Problemi basitleştirme & 12 & 34 & 35 \\
\hline
\end{tabular}

Tablo 2'deki değerlere göre, genel anlamda öğrencilerin herhangi bir eğitim olmaksızın stratejilerin çoğunu etkin bir biçimde kullanabildikleri söylenebilir. Özellikle tahmin ve kontrol, muhakeme etme, şekil çizme, denklem kurma ve bağıntı bulma stratejilerinin kullanım düzeyleri ortalamanın oldukça üstündedir. Bunun yanı sıra, geriye doğru çalışma, sistematik liste yapma ve problemi basitleştirme stratejilerinin kullanım düzeyleri zayıftır. Son testteki strateji kullanımı ile ilgili başarı yüzdeleri ise Tablo 3'te verilmiştir.

Tablo 3. Deney grubundaki öğrencilerin son testteki strateji kullanımları ile ilgili başarı yüzdeleri

\begin{tabular}{lrrr}
\hline \multirow{2}{*}{ Stratejiler } & \multicolumn{3}{c}{ Son test } \\
\cline { 2 - 4 } & $\begin{array}{r}\text { Elde edilen } \\
\text { puan }\end{array}$ & $\begin{array}{r}\text { Maksimum } \\
\text { puan }\end{array}$ & $\begin{array}{r}\text { Başarı } \\
\text { yüzdesi (\%) }\end{array}$ \\
\hline Sistematik liste yapma & 27 & 34 & 79 \\
\hline Tahmin ve kontrol & 12 & 34 & 35 \\
\hline Şekil çizme & 30 & 34 & 88 \\
\hline Denklem kurma & 34 & 34 & 100 \\
\hline Bağıntı bulma & 26 & 34 & 77 \\
\hline Geriye doğru çalışma & 20 & 34 & 59 \\
\hline Muhakeme etme & 26 & 34 & 77 \\
\hline Problemi basitleştirme & 21 & 34 & 62 \\
\hline
\end{tabular}

Tablo 3'teki veriler Tablo 2'dekilerle karşılaştırıldığında, tahmin ve kontrol ile muhakeme etme stratejileri hariç diğer altı stratejide başarı yüzdelerinin arttığı gözlenmektedir. Muhakeme etme stratejisindeki düşüş küçük oranda iken, tahmin ve kontrol etmedeki düşüş oldukça fazladır. En faz- la başarı artışı ise sistematik liste yapma ve geriye doğru çalışma stratejilerinde görülmüştür. Strateji kullanımlarının ön testten son teste değişimini daha ayrıntılı incelemek için strateji bazında hesaplanan $t$ değerleri Tablo 4'de verilmiştir.

Tablo 4. Strateji bazında t testi sonuçları

\begin{tabular}{lrcr}
\hline & \multicolumn{3}{c}{ Son test } \\
\cline { 2 - 4 } Stratejiler & $t$ & $s d$ & $p$ \\
\hline Sistematik liste yapma & -3.665 & 16 & $.002^{*}$ \\
\hline Tahmin ve kontrol & 4.854 & 16 & $.000^{*}$ \\
\hline Şekil çizme & -1.167 & 16 & .260 \\
\hline Denklem kurma & -2.582 & 16 & $.020^{*}$ \\
\hline Bağıntı bulma & -1.461 & 16 & .163 \\
\hline Geriye doğru çalışma & -3.567 & 16 & $.003^{*}$ \\
\hline Muhakeme etme & .824 & 16 & .422 \\
\hline Problemi basitleştirme & -1.926 & 16 & .072 \\
\hline "p<.05 & & &
\end{tabular}

Tablo 4'teki sonuçlara göre, sistematik liste yapma, denklem kurma ve geriye doğru çalışma stratejilerindeki başarı düzeyleri anlamlı derecede artmıştır. Daha önce de bahsedildiği gibi, düşüş yaşanan iki stratejiden biri olan tahmin ve kontroldeki değişim istatistiksel olarak anlamlıdır. Şekil çizme, bağıntı bulma, muhakeme etme ve problemi basitleştirme stratejilerinin başarı yüzdeleri ön testten son teste artmış olmasına rağmen, bu artışlar istatistiksel olarak anlamlı değildir.

İkinci Probleme İlişkin Bulgular

Tablo 5 'te ön ve son testteki toplam puanlara dayanarak yapılan betimsel istatistik ve $t$-Testi sonuçları görülmektedir.

Tablo 5. Ön ve son test sonuçları ile ilgili betimsel istatistik ve t-testi sonuçları

\begin{tabular}{lrrrr}
\hline & $x$ & SS & $t$ & $p$ \\
\hline Ön test & 9.42 & 3.30 & & \\
\hline Son test & 11.48 & 2.13 & -2.497 & $.024^{*}$ \\
\hline . $p<05$ & & & & \\
\hline
\end{tabular}
"p<.05

Tablo 5'ten de anlaşıldığı üzere, yapılan öğretim sonrasında öğrencilerin rutin olmayan problem çözmedeki genel başarı düzeyleri anlamlı derecede artmıştır.

\section{Sonuç ve Tartışma}

Araştırmanın ilk problemi "Rutin olmayan problem çözme eğitiminin dokuzuncu sınıf öğrencilerinin kullandıkları problem çözme stratejilerine etkisi nedir?" şeklindedir. Bu problemle ilgili elde edilen sonuçlara bakıldığında, ilk olarak öğrencilerin rutin olmayan problemlerle ilgili halihazırda geliştirilmeye hazır bir potansiyellerinin olduğu, herhangi bir eğitim verilmeksizin rutin olmayan problem çözme stratejilerini (üçü hariç) genelde etkin olarak kullandıkları söylenebilir. Bu sonuç, Salleh ve Zakaria (2009), Mabilangan ve diğerleri (2011) ve Yazgan (2013)'ın sonuçlarıyla da örtüşmektedir. Yeo (2009)'ya göre öğrencilerin problem çözmede yaşadığı sorunlardan biri olan strateji bilgi eksikliği, ön testte problemi basitleştirme, sistematik liste yapma ve geriye doğru çalış- 
ma stratejilerindeki düşük başarı düzeylerinin sebebi olarak değerlendirilebilir.

Eğitimin etkisine strateji bazında bakıldığında, özellikle sistematik liste yapma ve geriye doğru çalışma stratejilerinin başarı yüzdelerindeki artış oldukça yüksektir. Bu stratejilerin kullanım düzeyleri ön testte ortalamanın oldukça altında iken, son testte ortalamanın üstüne çıkmıştır. Bir önceki paragrafta bahsedilen strateji bilgi eksikliğinin verilen eğitimle giderildiği anlaşılmaktadır. Denklem kurma stratejisindeki artış, öğrencilerin verilen deneysel eğitimin yanı sıra normal matematik derslerinde de bu stratejiyi kullanmak zorunda olmaları ile açıklanabilir. Diğer stratejiler zaten eğitim öncesinde de iyi düzeyde kullanıldığı için, onların başarı düzeylerindeki artış istatistiksel olarak anlamlı çıkmamıştır. Buradaki en tartışmalı sonuç, tahmin ve kontrol stratejisinin başarı yüzdesindeki ciddi düşüştür. Bu durum, öğrenciler için ön testteki tahmin ve kontrol sorusunun son testtekine göre daha zor olduğunu düşündürmektedir. Şekil çizme stratejisi hem ön testte hem de son testte başarı düzeyi açısından ilk üçtedir. Bunun tersine problemi basitleştirme ve geriye doğru çalışma stratejileri ön ve son testte başarı düzeyi açısından son üçte kalmıştır. Bu durum, bu stratejilerin bilişsel anlamda daha karmaşık ve zor olduğunun göstergesi olabilir.

"Rutin olmayan problem çözme eğitiminin dokuzuncu sınıf öğrencilerinin bu tür problemleri çözmedeki başarılarına etkisi nedir?" şeklinde ifade edilen ikinci problemle ilgili elde edilen en önemli sonuç, verilen eğitimin öğrencilerin rutin olmayan problem çözme becerilerine olan olumlu etkisidir. Bu sonuç, Altun ve Arslan (2006) ve Kavgacı (2016) tarafından yapılan çalışmaların sonuçlarıyla benzeşmektedir.

Sınırılık ve öneriler

Çalışmada elde edilen sonuçların matematik eğitimi açısından en önemli getirisi, lise öğrencilerinin bilişsel anlamda rutin olmayan problem çözmeye yatkın olduklarını göstermesidir. Normalde lise matematik programında, öğretim ortamlarında veya ders kitaplarında neredeyse hiç yer almamasına rağmen, öğrenciler bu sorularla başarıyla başa çıkabilmektedirler. Ayrıca, verilen eğitim, strateji kullanımlarındaki başarılarını arttırmaktadır. Bundan dolayı, rutin olmayan problemler müfredat kapsamında matematik dersi ile bütünleştirilerek öğrencilerle buluşturulmalıdır. Tüm bunların yapılabilmesi için, öncelikle lise matematik öğretmenlerinin ve öğretmen adaylarının bu alanda hizmet içi ve hizmet öncesi eğitime tabi tutulması gerekmektedir.

Bu çalışma, giriş sınavında belirli bir puan alıp emsallerinden ön plana çıkmış dokuzuncu sınıf öğrencileri ile yapılmıştır. Bu çalışmanın sonuçları, lisenin diğer kademelerinde farklı akademik düzeydeki öğrencilerle yapılacak benzer çalışmalarla desteklenebilir. Bunun yanı sıra, ileride yapılacak olan çalışmalar için katılan öğrenci sayısının ve verilen deneysel eğitimin süresinin arttırılması önerilebilir. Yapılan çalışmada, öğrencilerin rutin olmayan problem çözme ile ilgili başarıları çoğunlukla onların yazılı cevaplarına dayanarak incelenmiştir. Illerideki çalışmalarda gözlem, görüşme gibi diğer veri toplama yöntemlerinin de kullanılması, bu konu ile ilgili daha detaylı bilgiye ulaşılmasını sağlayabilir. Son olarak, gerek ön ve son testte, gerekse deneysel eğitim sırasında kullanılan soru sayısının arttıııması, her bir stratejinin kullanımı ve gelişim düzeyi ile ilgili daha net bilgi edinilmesine yardım edebilir.

\section{Yayın Etiği Beyanı}

Bu araştırmanın planlanma, uygulama ve raporlama süreçlerinin tamamında "Yükseköğretim Kurumları Bilimsel Araştırma ve Yayın Etiği Yönergesi" kapsamında uyulması belirtilen tüm kurallara uyulmuştur. Yönergenin ikinci bölümü olan "Bilimsel Araştırma ve Yayın Etiğine Aykırı Eylemler" başlığı altında belirtilen eylemlerden hiçbiri gerçekleştirilmemiştir.

\section{Kaynakça}

Abedalaziz, N. (2001). Gender-related differences of Malaysian students in their solution processes of solving mathematical problems. OIDA International Journal of Sustainable Development, 2(7), 11-25

Altun, M. (2016). Illkokullarda matematik öğretimi (20. Baskı). Bursa: Aktüel Alfa Yayıncılık.

Altun, M. ve Arslan, Ç. (2006). Ilköğretim öğrencilerinin problem çözme stratejilerini öğrenmeleri üzerine bir çalışma. Uludağ Üniversitesi Eğitim Fakültesi Dergisi, 19(1), 1- 21.

Budak, i. (2012). Mathematical profiles and problem solving abilities of mathematically promising students. Educational Research and Review, 7(16), 344-350.doi: 0.5897/ERR12.009.

Büyüköztürk, Ş., Kılıç-Çakmak, E., Akgün, Ö. E., Karadeniz, Ş. ve Demirel, F. (2010). Bilimsel araştırma yöntemleri (7. baskı). Ankara: Pegem A Yayıncılık.

Elia, I., van den Heuvel-Panhuizen, M., \& Kolovou, A. (2009). Exploring strategy use and strategy flexibility in non-routine problem-solving by primary school high achievers in mathematics. ZDM Mathematics Education, 41, 605-618. doi: 10.1007/s11858-009-0184-6.

Fang, Y., Ho, K. F., Lioe, L. T., Wong, K. Y., \& Tiong Y. S. J. (2009). Developing the repertoire of heuristics for mathematical problem solving: Technical Report for Project CRP1/O4 TSK/JH. Singapore: Centre for Research in Pedagogy and Practice, National Institute of Education, Nanyang Technological University.

Hawkins, S., Truscott, J., \& Abebe, A. (2019). Active learning strategies: problem-based learning. In G. Kayingo \& V. McCoy Hass (Eds.), The health professions educator: A practical guide for new and established faculty (pp. 56-66). New York, NY: Springer.

Herr, T., \& Johnson, K. (2002). Problem-solving strategies: Crossing the river with dogs. USA: Key Curriculum Press.

Ishida, J. (2002). Students' evaluation of their strategies when they find several solution methods. The Journal of Mathematical Behavior, 21, 49-56. doi: 10.1016/S07323123(02)00102-5.

Kavgacı, Y. (2016). Matematik problemi çözme stratejileri öğretiminin dokuzuncu sınıf öğrencilerinin yaratıcılık düzeylerinin gelişimine etkisi incelenmesi (Yüksek lisans tezi). Necmettin Erbakan Üniversitesi Eğitim Bilimleri Enstitüsü, Konya. 
Kolovou, A., Van den Heuvel-Panhuizen, M., \& Bakker, A. (2009). Non-routine problem solving tasks in primary school mathematics textbooks-A needle in a haystack. Mediterranean Journal for Research in Mathematics Education, 8(2), 31-67.

Krulik, S., \& Rudnick, J. A. (1993). Reasoning and problem solving: A handbook for elementary school teachers. Needham Heights. Mass: Allyn and Bacon

Lawson, M. J. (1990). The case for instruction in the use of general problem-solving strategies in mathematics teaching: A comment on Owen and Sweller. Journal for Research in Mathematics Education, 21(5), 403-410.

Lee, N. H., Yeo, J. S. D., \& Hong, S. E. (2014). A metacognitive based instruction for primary four students to approach non-routine mathematical word problems. ZDM - the International Journal on Mathematics Education, 46(3), 465-480. doi: 10.1007/s11858-014-05996

Leng, N. W. (2008). Problem solving heuristics for primary school mathematics: a comprehensive guide. Singapore: Prentice Hall.

London, R. (2007). What is essential in mathematics education: A holistic viewpoint. MSOR Connections, 7(1), 3034 .

Mabilangan, R. A., Limjap, A. A., \& Belecina, R. R. (2012). Problem solving strategies of high school students on non-routine problems. Alipato: A Journal of Basic Education, 5, 23-45.

Marchis, I. (2012). Non-routine problems in primary mathematics workbooks from Romania. Acta Didactica Napocensia, 5(3), 49-56.

Milli Eğitim Bakanlığı (2018). Ortaöğretim matematik dersi öğretim programı. Ankara: Talim Terbiye Kurulu Başkanlığı.

Nancarrow, M. (2004). Exploration of metacognition and non-routine problem based mathematics instruction on undergraduate student problem-solving success (Doctoral dissertation). The Florida State University, Florida.

National Council of Teachers of Mathematics (2000). Principles and standards for school mathematics. Reston, VA: NCTM.

Novick, L. R., \& Bassok, M. (2005). Problem solving. In K. J. Holyoak \& R. G. Morrison (Eds.). The Cambridge handbook of thinking and reasoning, New York: Cambridge University Press.

Organisation for Economic Co-operation and Development. (2014a). PISA 2012 results: Creative problem solving (Volume V): Students' skills in tackling real-life problems. Paris: OECD. Retrieved from https://doi. org/10.1787/9789264208070.
Polya, G. (1957). How to solve it? Princeton: Princeton University Press.

Posamentier, A. S., \& Krulik, S. (2008). Problem solving strategies for efficient and elegant solutions, grades 6-12: A resource for the mathematics teacher. USA: Corwin Press.

Sahillioğulları, M. (2019). Farklı öğrenme stillerine sahip olan dokuzuncu sını öğrencilerinin problem çözme becerileri arasındaki farklııkların incelenmesi (Yüksek lisans tezi). Necmettin Erbakan Üniversitesi Eğitim Bilimleri Enstitüsü, Konya.

Salleh, F., \& Zakaria, E. (2009). Non-routine problem-solving and attitudes toward problem-solving among high achievers. International Journal of Learning, 16(5), 549559.

Sriraman, B. (2004). The characteristics of mathematical creativity. The Mathematics Educator, 14(1), 19-34.

Tiong, J. Y. S., Hedberg, J. G., \& Lioe, L. T. (2005). A metacognitive approach to support heuristic solution of mathematical problems. Proceedings of the Redesigning Pedagogy: Research, Policy, Practice Conference. Singapore: NIE.

Woodward, J., Beckmann, S., Driscoll, M., Franke, M., Herzig, P., Jitendra, A., ... Ogbuehi, P. (2012). Improving mathematical problem-solving in Grades 4 through 8: A practice guide. Washington, D.C.: National Center for Education Evaluation and Regional Assistance, Institute of Education Sciences, U.S. Department of Education.

Yazgan,Y., (2013). Non-routine mathematical problem-solving at high school level and its relation with success on university entrance exam. US-China Education Review $A$, 3(8). 571-579.

Yazgan, Y., Arslan, Ç., Tapan, M. S., Memnun, D. S., Akkaya, R., Çelebioğlu, B. ve Yılmaz, A. (2013) Ilköğretim ve lise öğrencilerinin sıradışı problemleri çözme yeterlilikleri (Proje No. E(U)-2009/49). Bursa Uludağ Üniversitesi web sitesinden erişilen adres: http://bap.uludag.edu. $\mathrm{t} r /$ ?act $=$ guest $\&$ act $2=$ projeler $\&$ act $3=$ detay $\&$ mode $=-$ clear\&mode $=$ clear\&id $=300$

Yeo, K. K. J. (2009). Secondary 2 students' difficulties in solving non-routine problems. International Journal for Mathematics Teaching and Learning, 8,1-30.

Yılmaz, R. (2019). Sınıf öğretmeni adaylarının rutin olmayan problemleri çözme süreçleri. Erzincan Üniversitesi Eğitim Fakültesi Dergisi, 21(2), 30-49. 